\title{
HPLC/ICP Mass Spectrometric Study of the Selenium Incorporation into Cyanobacterial Metallothionein Induced under Heavy-Metal Stress
}

\author{
Kikuo Takatera*, Nobukazu Osaki**, Hiroyoshi Yamaguchi** and Tadashi Watanabe* \\ *Institute of Industrial Science, University of Tokyo, Roppongi, Minato, Tokyo 106, Japan \\ ** Kochi National College of Technology, Monobe, Nangoku, Kochi 783, Japan
}

\begin{abstract}
Selenium is a toxic element which can cause environmental pollution. Its uptake and incorporation by $\mathrm{Zn}^{2+}$-induced metallothionein (MT) biosynthesis in a cyanobacterium were studied by means of high-performance liquid chromatography (HPLC) with inductively coupled plasma mass spectrometric (ICPMS) detection. When we cultured the cells in selenite-enriched media, as much as $60 \%$ of the total selenium in the water-soluble cell components was incorporated into MT, which exists as two major isoforms but occupies a very minor fraction of the overall proteins. Existence of two pathways has been shown for the first time for selenium incorporation into the cyanobacterial MT; one is the S-Se bonding which can be reductively broken by 2-mercaptoethanol, and the other is the formation of selenocysteine followed by its incorporation into the MT peptide chain. No essential difference was noted between selenite and selenate regarding the uptake or the incorporation of Se. The present HPLC/ICPMS system can elucidate biological processes of environmental chemical importance at the molecular level.
\end{abstract}

Keywords Inductively coupled plasma mass spectrometry, high-performance liquid chromatography, metallothionein, isoform, zinc, selenium, selenocysteine, cyanobacterium, heavy metal

Metallothioneins (MTs) are a class of low molecular weight, cysteine-rich, metal-binding proteins found in various organs of animals, plants, eukaryotic microorganisms and prokaryotes including cyanobacteria (blue-green algae). ${ }^{1} \quad$ MTs are induced when such heavy metal ions as $\mathrm{Cu}^{2+}, \mathrm{Zn}^{2+}$ and $\mathrm{Cd}^{2+}$ are administered in high amounts. Contamination of aquatic microorganisms with heavy metals is one of the major concerns in environmental chemistry and biochemistry since they are, as accumulators of heavy metals, the primary food which enters trophic chains in the aquatic system. Cyanobacteria can accumulate heavy metals to a concentration several orders-of-magnitude higher than in the surrounding medium. Most of the incorporated excess heavy metals are converted into MT.

Selenium, though toxic when dosed in high amounts ${ }^{2,3}$, is an essential nutrient that is taken up in several different chemical forms. The bioavailability and metabolism of different chemical species of Se in the diet are receiving much attention in nutrition science. Dietary Se in the form of amino acids such as selenomethionine and selenocysteine is more readily absorbed than inorganic selenite and selenate. ${ }^{4}$ At the present time, when environmental pollution by selenium used in various advanced devices is becoming of increasing concern, its fate analysis in the biosphere is also of much importance.

Although selenium itself does not trigger the biosynthesis of MT, there are a few reports indicating the association of Se with mammalian MTs by Cd-induced synthesis of MT. ${ }^{5}$ In some higher plants, uptake of selenate or selenite leads to the synthesis of amino acids, selenocysteine or selenomethionine, in a manner similar to sulfur metabolism. ${ }^{3}$ The toxicity of Se to plant species supposedly arises from indiscriminate incorporation of Se in place of $S$ into $S$-containing amino acids of cellular constituents, since organoselenium compounds are generally less stable and more reactive than the sulfur counterparts. ${ }^{6}$ However, it still remains unclear whether selenocysteine does actually enter the polypeptide chains. To our knowledge, no report has unambiguously identified specific protein(s) with which selenium is associated in plants or microorganisms.

For the speciation of cyanobacterial MT, we have developed a measurement system by combining highperformance liquid chromatography (HPLC) with inductively coupled plasma mass spectrometry (ICPMS). ${ }^{7}$ In the present work, this technique is applied to the examination of in vivo selenium association with cyanobacterial MT, especially the identification of the chemical form(s) of Se in MT, by use of size exclusion (SE)-, reversed-phase (RP)- and cation exchange (CE)HPLC.

\section{Experimental}

\section{Materials}

Seleno-D,L-cystine and seleno-L-methionine were purchased from Sigma; dithioerythritol (DTE), 2- 
mercaptoethanol and iodoacetic acid were purchased from Wako Pure Chemical Industries; and dithiothreitol (DTT) was purchased from Tokyo Kasei Kogyo. All were used without further purification. Metal standard solutions were prepared by diluting and mixing commercial standard solutions for AAS (Wako Pure Chemical Industries). Water deionized with a Millipore Milli-Q system was used throughout.

\section{Culture conditions}

A cyanobacterium Anacystis nidulans R-2 was grown in a 3-L of $\mathrm{Cu}$-depleted $\mathrm{BG}-11$ medium $^{8}$ with $10 \mu \mathrm{M}$ of $\mathrm{ZnCl}_{2}$ and $30 \mu \mathrm{M}$ of $\mathrm{Na}_{2} \mathrm{SeO}_{3}$ added at $23^{\circ} \mathrm{C}$ under fluorescent lamps (ca. $1000 \mathrm{~lx}$ ). In additional experiments, $\mathrm{Na}_{2} \mathrm{SeO}_{4}$ was employed in place of $\mathrm{Na}_{2} \mathrm{SeO}_{3}$. Cells were harvested after culturing for about 3 weeks, until the growth reached a stationary phase.

\section{Sample preparation}

The cells harvested by centrifugation were washed three times with $10 \mathrm{ml}$ of a $10 \mathrm{mM}$ Tris- $\mathrm{HCl}$ buffer (pH 8.0) containing $1 \mathrm{mM}$ EDTA, to remove metal ions reversibly bound to the cell wall. Then they were homogenized by ultrasonification in $2 \mathrm{ml}$ of a cold $10 \mathrm{mM}$ Tris- $\mathrm{HCl}$ buffer (pH 8.0) containing $1 \mathrm{mM}$ dithiothreitol (DTT). The homogenate was then centrifuged at $143000 \times g$ for $1 \mathrm{~h}$ at $4^{\circ} \mathrm{C}$; the resulting supernatant was submitted to the SE-HPLC/ICPMS measurements for the speciation of MT.

\section{Fractionation of cytosolic proteins}

The supernatant was separately chromatographed on a preparative-scale Sephadex G-75 column $(2.6 \times 75 \mathrm{~cm})$. The elution buffer was $10 \mathrm{mM} \mathrm{NH} \mathrm{NHCO}_{3}$ containing $5 \mathrm{mM}$ 2-mercaptoethanol, with a flow rate of $1.0 \mathrm{ml} / \mathrm{min}$ and a fraction volume of $3.15 \mathrm{ml}$. The fractions were monitored for absorbance at $254 \mathrm{~nm}$, and the concentrations of $\mathrm{Zn}$ and $\mathrm{Se}$ in each fraction were determined by ICPMS. The fractions corresponding to the molecular weight of about 8000 and containing $\mathrm{Zn}$ and Se were collected and lyophilized for the speciation of MT isoforms and selenium species.

\section{Speciation of selenium species}

Carboxymethylation of the MT fraction was performed with iodoacetic acid. ${ }^{9}$ One milligram of the lyophilized sample was dissolved in $50 \mu$ of $0.2 \mathrm{M}$ Tris$\mathrm{HCl}$ buffer ( $\mathrm{pH} 8.8$ ) containing $8 \%$ (w/v) sodium dodecyl sulfate (SDS), $50 \%(\mathrm{v} / \mathrm{v})$ glycerol and $5 \mu \mathrm{l}$ of $0.2 \mathrm{M}$ DTE; the mixture was then boiled for $5 \mathrm{~min}$. After the reaction mixture was cooled, $7 \mu \mathrm{l}$ of a $1 \mathrm{M}$ iodoacetic acid solution of $\mathrm{pH}$ adjusted to about 8 with $\mathrm{NaOH}$ just before use, was added to the mixture, followed by incubation at $50^{\circ} \mathrm{C}$ for $15 \mathrm{~min}$. The reaction mixture was then dialyzed against water and lyophilized to obtain the derivatized proteins for hydrolysis.

The lyophilized sample was re-suspended in $6 \mathrm{M} \mathrm{HCl}$ for hydrolysis. An aliquot of the acid suspension was

Table 1 Chromatographic conditions and ICPMS operating procedures

\begin{tabular}{|c|c|c|c|}
\hline & Separation of MT & Separation of MT isoforms & Separation of Se species \\
\hline \multicolumn{4}{|c|}{ Chromatographic conditions } \\
\hline \multirow[t]{3}{*}{ Column } & Size exclusion (SE) & Reversed phase (RP) & Cation exchange (CE) \\
\hline & $\begin{array}{l}\text { Asahipak GFA-30F } \\
\text { (Asahi Chem. Ind.) }\end{array}$ & Capcellpak $\mathrm{C}_{8}$ (Shiseido) & Nucleosil 100-5SA (M. Nagel) \\
\hline & $7.6 \mathrm{~mm}$ i.d. $\times 300 \mathrm{~mm}$ & $4.5 \mathrm{~mm}$ i.d.$\times 150 \mathrm{~mm}$ & $4.6 \mathrm{~mm}$ i.d. $\times 250 \mathrm{~mm}$ \\
\hline Mobile phase & $\begin{array}{l}50 \mathrm{mM} \text { Tris- } \mathrm{HCl}(\mathrm{pH} 7.5) \\
+0.2 \mathrm{M}\left(\mathrm{NH}_{4}\right)_{2} \mathrm{SO}_{4}, \\
0.1 \mathrm{mM} \text { EDTA }\end{array}$ & $\begin{array}{l}9: 91(\mathrm{v} / \mathrm{v}) \text { acetonitrile: } \\
50 \mathrm{mM} \text { Tris- } \mathrm{HCl}(\mathrm{pH}=7.5) \\
\text { +0.1 mM EDTA }\end{array}$ & $\begin{array}{l}\text { A: } 25 \mathrm{mM} \mathrm{NH}_{4} \mathrm{H}_{2} \mathrm{PO}_{4}(\mathrm{pH} 3.0) \\
\text { B: } 25 \mathrm{mM}\left(\mathrm{NH}_{4}\right)_{2} \mathrm{HPO}_{4}(\mathrm{pH} 7.0)\end{array}$ \\
\hline Elution profile & isocratic & isocratic & $\begin{array}{l}\text { linear gradient: } \\
0-20 \text { min: } 0-67 \% \text { B }\end{array}$ \\
\hline Flow rate $\left(\mathrm{ml} \mathrm{min}^{-1}\right)$ & 0.8 & 1.0 & 1.0 \\
\hline Injection volume $(\mu \mathrm{l})$ & 20 & 20 & 20 \\
\hline
\end{tabular}

ICPMS operating procedures

\begin{tabular}{|c|c|c|c|}
\hline Argon gas flow rate $(1 \mathrm{~m}$ & & & \\
\hline outer & 18.0 & 17.5 & 18.0 \\
\hline auxiliary & 1.0 & 1.6 & 1.0 \\
\hline nebulizer & 1.2 & 0.90 & 1.2 \\
\hline $\mathrm{O}_{2}$ fraction in nebulizer & 0 & 0.08 & 0 \\
\hline Forward power $(\mathrm{kW})$ & 1.2 & 1.5 & 1.2 \\
\hline Isotopes monitored & ${ }^{68} \mathrm{Zn},{ }^{78} \mathrm{Se}$ & ${ }^{64} \mathrm{Zn},{ }^{78} \mathrm{Se}$ & ${ }^{64} \mathrm{Zn},{ }^{78} \mathrm{Se}$ \\
\hline
\end{tabular}


sealed in a glass ampoule under reduced pressure after repeated evacuation. The sealed ampoule was heated for $40 \mathrm{~h}$ at $110^{\circ} \mathrm{C}$, then opened; the contents were dried in vacuo. The hydrolysate was re-dissolved in $50 \mathrm{mM}$ Tris- $\mathrm{HCl}$ buffer ( $\mathrm{pH} \mathrm{7.0)}$ for ion exchange chromatography.

Carboxymethylated (CM-) selenocysteine standard was prepared by the method of Brown and Shrift. ${ }^{10}$ Ten milligrams of selenocystine was suspended in $3 \mathrm{ml}$ Tris$\mathrm{HCl}$ (pH 8.6), to which $0.1 \mathrm{ml}$ of 2-mercaptoethanol was added to reduce the selenocystine into selenocysteine at room temperature for $4 \mathrm{~h}$ under $\mathrm{N}_{2}$. Selenocysteine was then carboxymethylated by addition of iodoacetic acid ( $500 \mathrm{mg}$ ) dissolved in $1 \mathrm{ml}$ of $1 \mathrm{M} \mathrm{NaOH}$, followed by incubation at room temperature for $15 \mathrm{~min}$ under $\mathrm{N}_{2}$. The mixture was applied with the MT hydrolysate to CEHPLC/ICPMS for the assay of selenocysteine in MT.

\section{HPLC/ICPMS measurements}

The HPLC system was composed of a JASCO 880-PU dual-piston HPLC pump, a Rheodyne 7125 injector with a 20- $\mu$ l injection loop, and a Rheodyne 7030 switching valve and an appropriate analytical column. The chromatographic conditions are summarized in Table 1. For SE-HPLC, $0.2 \mathrm{M}\left(\mathrm{NH}_{4}\right)_{2} \mathrm{SO}_{4}$ was added in the eluent to attain quantitative protein recovery. For SE- and RP-HPLC, $0.1 \mathrm{mM}$ EDTA was added in the eluent to prevent the adhesion of inorganic metal ions to the separation gel, such adhesion tends to generate anomalous metal peaks in subsequent runs. In the CEHPLC/ICPMS measurement, changes in the sensitivity of ICPMS caused by the pH-gradient elution during chromatographic runs were less than $5 \%$ : this was comparable to the value obtained under isocratic elution. Hence no sensitivity corrections were made on any measurements.

The ICPMS apparatus used was SPQ-6100 (Seiko Instruments Inc.). Table 1 summarizes the instrumental operating conditions of ICPMS for each mode of measurement. The chromatogram peak areas and retention times were determined by use of the SPQ-6100 software and an NEC PC-9801 computer. The choice of the third abundant $\mathrm{Zn}$ isotope mass number $(\mathrm{m} / z=$ $68)$, instead of the first $(m / z=64)$ and second $(m / z=66)$ abundant isotopes, in the SE-HPLC/ICPMS operation is because of severe interferences from polyatomic ions $\mathrm{S}_{2}{ }^{+}$and $\mathrm{SO}_{2}{ }^{+}$produced in the argon plasma from $\mathrm{SO}_{4}{ }^{2-}$ in the eluent. Similarly, the second abundant mass number of 78 was chosen for the Se monitoring since the most abundant isotope $(m / z=80)$ undergoes interference from argon dimer ions $\mathrm{Ar}_{2}{ }^{+}$.

HPLC/ICPMS determination of elements was achieved via peak-area calibration using metal standard solutions. By controlling the switching valve located between the injection valve and the HPLC, the system can be operated in a flow-injection (FI) mode (FI/ ICPMS). This facilitated quantitation of samples and standards under the same flow conditions as for the HPLC column. Thus, as soon as the sample elution and

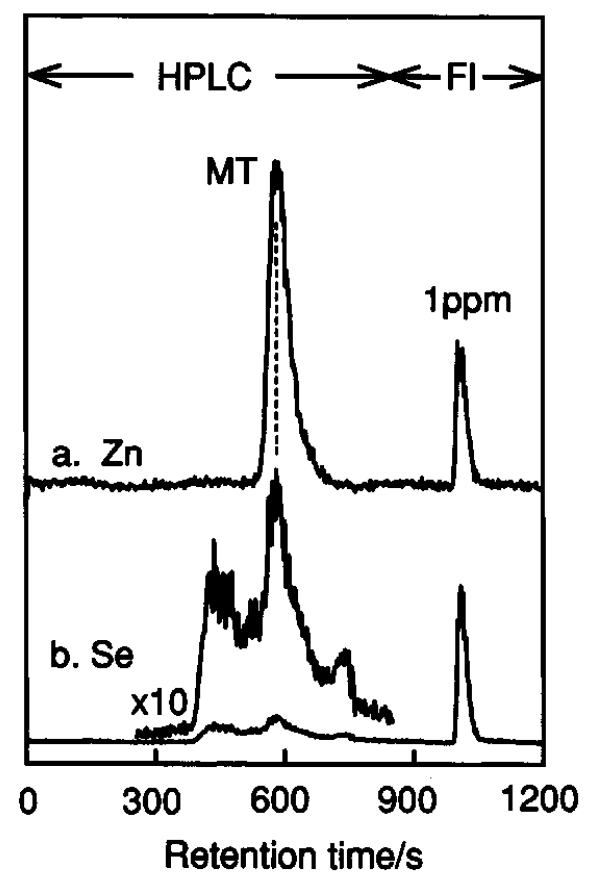

Fig. 1 SE-HPLC/ICPMS chromatograms for the watersoluble fraction of cyanobacterium (Anacystis nidulans R-2) cultured in the BG-11 medium containing $\mathrm{ZnCl}_{2}(10 \mu \mathrm{M})$ and $\mathrm{Na}_{2} \mathrm{SeO}_{3}(30 \mu \mathrm{M})$.

ICPMS detection were completed within about $900 \mathrm{~s}$ (SE- and CE-HPLC) or 1200 s (RP-HPLC), the system was changed to the FI/ICPMS mode and a standard $\mathrm{Zn}$ and Se solution was injected for metal quantitation. A batch measurement was complete within $1200 \mathrm{~s}$ (SE- and CE-HPLC) or $1500 \mathrm{~s}$ (RP-HPLC).

\section{Results and Discussion}

\section{Speciation of MT by SE-HPLC/ICPMS}

Figure 1 shows the SE-HPLC/ICPMS chromatograms, monitored at mass numbers of $\mathrm{Zn} \mathrm{(68)} \mathrm{and} \mathrm{Se}$ (78), for the water-soluble fraction of cyanobacterial homogenates. The peaks at $1000 \mathrm{~s}$ are $1-\mathrm{ppm}$ standard $\mathrm{Zn}$ and Se peaks detected in the FI/ICPMS mode. The peaks at a retention time of $580 \mathrm{~s}$ are assignable to the $\mathrm{Zn}$ MT induced in the cyanobacterium. ${ }^{7 \mathrm{c}}$ Clearly, $\mathrm{Zn}$ is associated exclusively with the MT fraction. On the other hand, there are two major Se peaks in the elution profile. One is eluted just after the column void volume (435 s) associated with large molecular weight proteins, and the other is eluted exactly at the peak of MT. Selenium in the latter peak represented $58 \%$ of the total Se that was eluted from this column. A minor Se peak at $740 \mathrm{~s}$ is an unidentified, low molecular weight Se compound.

Figure 2 shows the Sephadex G-75 elution profiles of the same sample as for Fig. 1. Fractions in the elution volume of $100-232$ and $232-279 \mathrm{ml}$ were separately collected and lyophilized. The weight of the former 


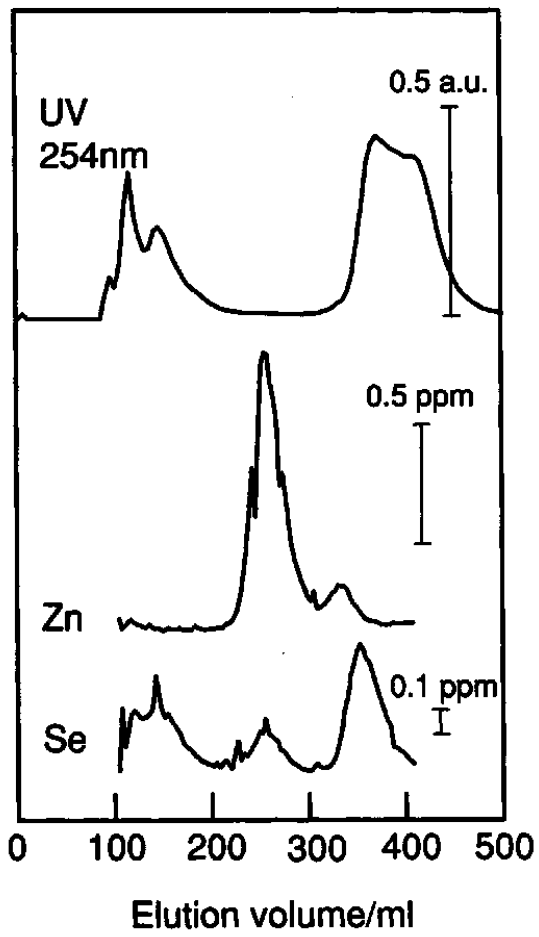

Fig. 2 Sephadex G-75 elution profiles for the water-soluble fraction of cyanobacterium. See text for details.

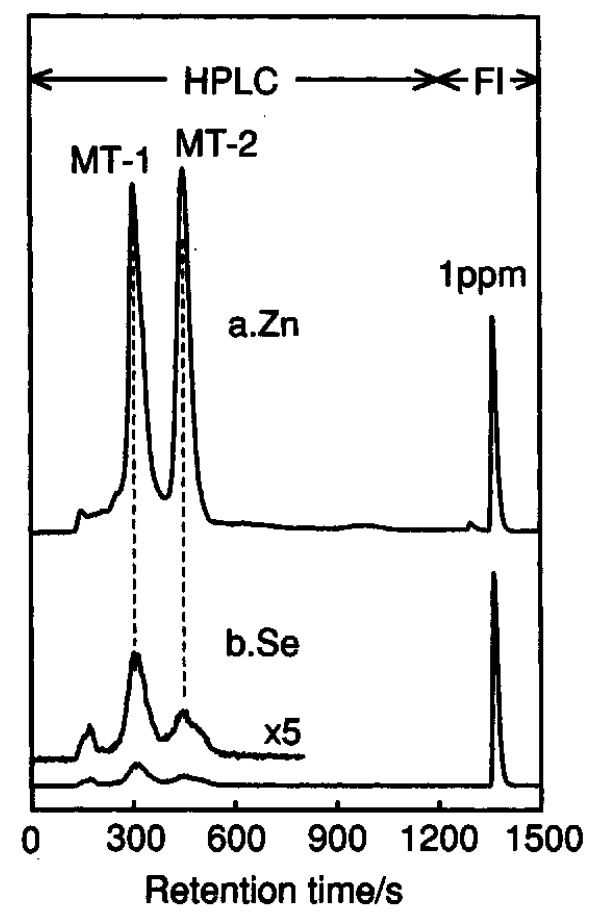

Fig. 3 RP-HPLC/ICPMS chromatograms for the MT fraction obtained by Sephadex G-75 gel filtration of the water-soluble fraction of cyanobacterium.

fraction was 31.1 , and that of the latter was $3.0 \mathrm{mg}$. The fraction in the elution volume of $232-279 \mathrm{ml}$ essentially consists of MT, which is barely detectable in the UV absorbance chromatogram. From these data, the $\mathrm{Se} /$ protein ratio for MT was calculated to be roughly 14 times higher than that for other, heavier proteins: this shows the selective incorporation of Se into MT. The MT fraction was stored for further analysis.

The relative intensity of the lower molecular weight band $(320-400 \mathrm{ml})$ is much stronger in the Se-chromatogram of Fig. 2 than that in the Se-chromatogram in Fig. 1: the fractions of the lower molecular weight component are 9 and 36\% in Figs. 1 and 2, respectively. This is suggestive of a release of Se from the MT fraction during separation in the Sephadex G-75 column. A portion of Se has probably been covalently linked to the sulfhydryl groups of cysteine residues in MT, and $5 \mathrm{mM}$ 2-mercaptoethanol in the eluent reductively cleaved the $\mathrm{S}-\mathrm{Se}$ bond. If this is indeed the case, the fraction of Se bound to MT via the S-Se bond is estimated to be $36-9=27 \%$. The existence of S-Se type bonding was demonstrated by Weser $e t$ al. by X-ray photoelectron spectroscopy in vitro. ${ }^{11}$ They reported that a selenotrisulfide was formed when selenite was incubated with a Zn-MT apoprotein prepared from rat liver.

\section{Speciation of MT isoforms by RP-HPLC/ICPMS}

Reversed-phase HPLC is a powerful means for the separation of MT isoforms, because it can even effectively separate peptides that differ in their composition only by a single amino acid. ${ }^{12}$ When the cyanobacterial MT fraction collected as described above was submitted to separation and detection by RPHPLC/ICPMS, two major MT peaks were detected, as displayed in Fig. 3. After carboxymethylation following SDS-PAGE, each of these peaks gave a single homogeneous band on the gel by silver staining (data not shown). These two MT isoforms exhibited different Se and $\mathrm{Zn}$ binding properties. Thus, the $\mathrm{Se} / \mathrm{Zn}$ molar ratios of the forms at retention times of 300 and $450 \mathrm{~s}$ were 0.07 and 0.04 , respectively. The molecular level picture underlying such a difference is not known at present, and is to be elucidated in future work.

Olafson et al. reported that a Cd-MT from another cyanobacterial strain (Synechococcus strain TX-20) was separated into seven isoforms by reversed-phase column chromatography. ${ }^{13}$ They attributed the large number of separable MT forms to the nature of metals incorporated therein and to the degree of metal saturation in MT. Since a single metal ion $\left(\mathrm{Zn}^{2+}\right)$ was used for the MT induction and hence $\mathrm{Zn}$ was the sole metal incorporated into MT in the present work, the two MT isoforms probably differ in the amino acid composition. Thus, the RP-HPLC/ICPMS detection is useful for determining the metal distribution among the MT isoforms as well as the selective accumulation of selenium in a particular isoform.

\section{Speciation of Se species by CE-HPLC/ICPMS}

Selenocysteine is highly susceptible to oxidative degradation, because the selenol group has a significantly lower oxidation redox potential than its sulfur counter- 


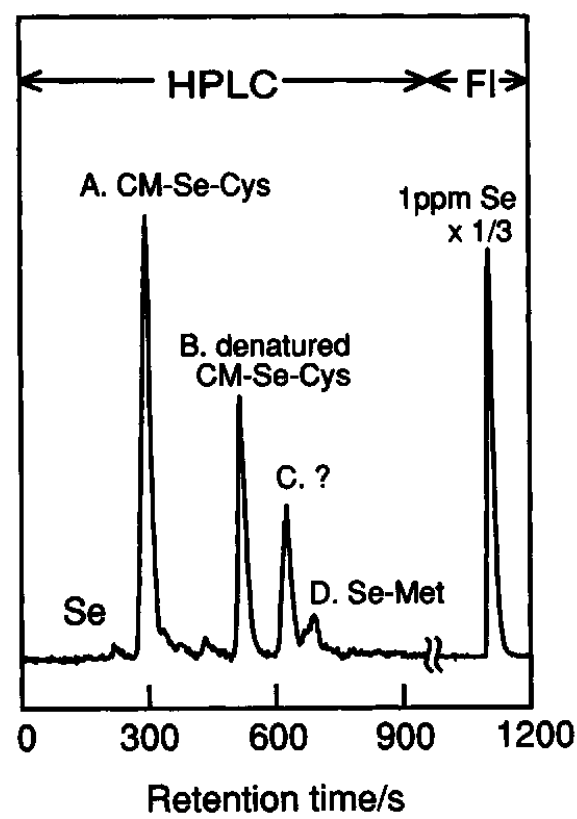

Fig. 4 CE-HPLC/ICPMS chromatograms for the hydrolyzed MT fraction obtained by Sephadex G-75 gel filtration of the water-soluble fraction of cyanobacterium.

part. ${ }^{6}$ To stabilize selenocysteine and prevent its degradation, the carboxymethyl derivative was synthesized by addition of iodoacetic acid to the $\mathrm{Zn}-\mathrm{MT}$ fraction obtained above. Figure 4 shows a cation exchange (CE) chromatographic elution profile of the hydrolysate of the carboxymethylated MT fraction. The peak assignments were done by adding standard CM-selenocysteine and selenomethionine to the sample. The chromatogram reveals that $46 \%$ of Se exists as CM-selenocysteine (A) and $4 \%$ as selenomethionine (D). Peak B is assignable to a denatured form of CM-selenocysteine, in view of the observation that standard $\mathrm{CM}$-selenocysteine stored in an acidic solution $(0.1 \mathrm{M} \mathrm{HCl})$ was also converted into a species giving peak B. Probably peak $B$ originates in an intramolecularly condensed form of CM-selenocysteine, by analogy with the reaction found for CM-cysteine. ${ }^{14}$ The sum of peaks A and B thus reveals that $70 \%$ of $\mathrm{Se}$ in MT exists in the form of selenocysteine. Peak C, amounting to $19 \%$ of the total Se, remains unidentified. Despite this uncertainty, this result clearly indicates that selenocysteine is the dominant form of the tightly bound selenium in cyanobacterial MT.

\section{Selenate versus selenite for incorporation of Se into MT}

Of different chemical forms of selenium usually present in soils, only the inorganic anions, selenate $\left(\mathrm{SeO}_{4}{ }^{2-}\right)$ and selenite $\left(\mathrm{SeO}_{3}{ }^{2-}\right)$, are known to be toxic to higher plants. This toxicity can be attributed to a combination of three factors: (i) both anions are readily absorbed by roots and translocated to other parts of the plant, (ii) both are metabolized into organoselenium compounds within the cell, and (iii) these metabolites act as analogues of essential sulfur compounds and thereby interfere with biochemical reactions. ${ }^{3}$

To see if the anionic form affects the mode of Se incorporation into different compounds in vivo, the cyanobacterium was cultured in $\mathrm{Na}_{2} \mathrm{SeO}_{4}$ - and $\mathrm{Na}_{2} \mathrm{SeO}_{3}-$ containing culture media and the resulting $\mathrm{Zn}$ and Se distributions were compared. The results are summarized in Table 2. A slight difference was noted between selenite and selenate in the RP-HPLC/ICPMS chromatograms. When dosed with $\mathrm{Na}_{2} \mathrm{SeO}_{4}$, a relatively large portion of $\mathrm{Zn}$ and $\mathrm{Se}$ was eluted at the void volume. The release of $\mathrm{Zn}^{2+}$ from MT entailed the release of Se. This may reflect the existence of $\mathrm{Zn}-\mathrm{Se}-$ $R$ bonds in which $R$ is any residue that is not bound to the apo-MT, though further study is needed to substantiate this speculation. Except for such a minor difference, no clear difference was noted between $\mathrm{SeO}_{4}{ }^{2-}$ and $\mathrm{SeO}_{3}{ }^{2-}$ regarding the Se-incorporation in MT. This suggests that selenate is reduced into selenite after the uptake by the cyanobacterial cell. We tentatively propose that sulfate-reducing enzymes are responsible for the selenate reduction. ${ }^{3}$

Though the function of selenocysteine as an integral component of some mammalian and microbial enzymes is well-documented ${ }^{2}$, and the ability of plants to synthesize this selenoamino acid has been demonstrated ${ }^{3}$, almost nothing is known about the mode of its incorporation into proteins of plants or microorganisms.

Table 2 Content (\%) of Se or $\mathrm{Zn}$ in three different fractions against the total Se or $\mathrm{Zn}$ detected chromatographically, for cyanobacterial cells cultured in the BG-11 medium containing (A) $\mathrm{ZnCl}_{2}(10 \mu \mathrm{M})$ and $\mathrm{Na}_{2} \mathrm{SeO}_{3}(30 \mu \mathrm{M})$ or $(\mathrm{B}) \mathrm{ZnCl}_{2}(10 \mu \mathrm{M})$ and $\mathrm{Na}_{2} \mathrm{SeO}_{4}(30 \mu \mathrm{M})$

\begin{tabular}{|c|c|c|c|c|c|c|c|c|c|c|c|c|}
\hline & \multicolumn{3}{|c|}{ SE-HPLC/ICPMS } & \multicolumn{3}{|c|}{ Sephadex G-75 } & \multicolumn{3}{|c|}{ RP-HPLC/ICPMS } & \multicolumn{3}{|c|}{ CE-HPLC/ICPMS } \\
\hline & $>\mathrm{MT}$ & MT & $<\mathrm{MT}$ & $>\mathrm{MT}$ & MT & $<\mathrm{MT}$ & v.v. ${ }^{a}$ & MT-1 & MT-2 & Se-Cys & Se-Met & peak $C^{b}$ \\
\hline $\begin{array}{r}\text { (A) } \mathrm{Se} \\
\mathrm{Zn}\end{array}$ & $\begin{array}{c}33 \\
\text { N.D. }\end{array}$ & $\begin{array}{r}58 \\
\text { ca. } 100\end{array}$ & $\begin{array}{c}9.1 \\
\text { N.D. }\end{array}$ & $\begin{array}{c}37 \\
\text { N.D. }\end{array}$ & $\begin{array}{l}27 \\
85\end{array}$ & $\begin{array}{r}36 \\
3\end{array}$ & $\begin{array}{l}8.7 \\
1.3\end{array}$ & $\begin{array}{l}52 \\
46\end{array}$ & $\begin{array}{l}29 \\
44\end{array}$ & 70 & 4.2 & 19 \\
\hline $\begin{array}{l}\text { (B) } \mathrm{Se} \\
\mathrm{Zn}\end{array}$ & $\begin{array}{c}29 \\
\text { N.D. }\end{array}$ & $\begin{array}{r}63 \\
\text { ca. } 100\end{array}$ & $\begin{array}{c}8.0 \\
\text { N.D. }\end{array}$ & $\begin{array}{l}37 \\
4.6\end{array}$ & $\begin{array}{l}32 \\
87\end{array}$ & $\begin{array}{l}31 \\
8.4\end{array}$ & $\begin{array}{l}38 \\
6.0\end{array}$ & $\begin{array}{l}36 \\
58\end{array}$ & $\begin{array}{l}20 \\
26\end{array}$ & 74 & 1.6 & 13 \\
\hline
\end{tabular}

$>\mathrm{MT}$, larger molecular weight fraction; MT, MT fraction; <MT, lower molecular weight fraction. a. Void volume peak. b. Unidentified species (see Fig. 4). 
The present study has unequivocally demonstrated the existence of two pathways for Se incorporation in the cyanobacterial MT: (a) covalent binding of Se to MT as selenocysteine and (b) S-Se type binding which can be broken by the action of 2-mercaptoethanol.

The human body can absorb dietary selenium in the form of such amino acids as selenomethionine and selenocysteine more easily than it can the inorganic selenite and selenate. ${ }^{4}$ We have found here that coadministration of $\mathrm{Zn}^{2+}$ and selenite or selenate in cyanobacteria leads to the incorporation of $\mathrm{Se}$ in the peptide chain of MT, and selenocysteine is the dominant form of the Se compound. This may be hazardous for biological activities. Toxic elements including heavy metals are accumulated in the environment through human activity. ${ }^{15}$ Such biotransformation of $\mathrm{Se}$ in microorganisms may cause increased accumulation of $\mathrm{Se}$ in edible living organisms. Further work is necessary to clarify such synergistic effects of toxic elements on the biosphere.

We thank Shigeki Matsuhisa for his help with the experiments. This work was supported in part by the Tokyo Ohka Foundation for the Promotion of Science and Technology and by a Grant-in-Aid for Scientific Research (No. 05680457) from the Ministry of Education, Science and Culture.

\section{References}

1. (a) "Metallothionein", ed. J. H. R. Kägi and M. Nordberg, Birkhäuser Verlag, Basel, 1979; (b) "Metallothionein II", ed. J. H. R. Kägi and Y. Kojima, Birkhäuser Verlag, Basel, 1987.
2. T. C. Stadtman, Ann. Rev. Biochem., 49, 93 (1980).

3. T. A. Brown and A. Shrift, Biol. Rev., 57, 59 (1982).

4. P. B. Moser-Veillon, A. R. Aangels, K. Y. Patterson and C. Veillon, Analyst [London], 117, 559 (1992).

5. V. K. Paliwal, L. Lyall, R. Prasad, S. Gulati, M. Sharma and R. Nath, Biochem. Intl., 4, 399 (1982); (b) A. J. Viljoen and A. L. Tappel, J. Inorg. Biochem., 34, 277 (1988).

6. R. J. P. Williams, "New Trends in Bioinorganic Chemistry", pp. 253 - 260, Academic Press, New York, 1978.

7. (a) K. Takatera and T. Watanabe, Anal. Sci., 7, 695 (1991); (b) ibid., 8, 469 (1992); (c) ibid., 9, 19 (1993). (1993).

8. R. W. Castenholz, "Methods in Enzymology", ed. L. Packer and A. N. Glazer, Vol. 167: "Cyanobacteria," pp. 68 - 93, Academic Press, San Diego, 1987.

9. M. Kimura, S. Koizumi and F. Otsuka, "Methods in Enzymology", ed. J. F. Riordan and B. L. Vallee, Vol. 205: "Metallobiochemistry. Part B. Metallothionein and Related Molecules," pp. 114 - 119, Academic Press, San Diego, 1991.

10. T. A. Brown and A. Shrift, Plant Physiol., 66, 758 (1980).

11. U. Weser, G. Sokolowski and W. Pilz, J. Electr. Spectr. Rel. Phenom., 10, 429 (1977).

12. M. P. Richards, "Methods in Enzymology", ed. J. F. Riordan and B. L. Vallee, Vol. 205: Metallobiochemistry. Part B. Metallothionein and Related Molecules, pp. 217 238, Academic Press, San Diego, 1991.

13. R. W. Olafson, W. D. McCubbin and C. M. Kay, Biochem. J., 251, 691 (1988).

14. A. F. Bradbury and D. G. Smyth, Biochem. J., 131, 637 (1973).

15. J. O. Nriagu and J. M. Pacyna, Nature [London], 333, 134 (1988).

(Received March 18, 1994)

(Accepted May 12, 1994) 